\title{
After methyl bromide: No easy answers
}

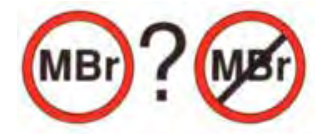

W hen the 1990 Clean Air Act decreed that methyl bromide would be phased out within 10 years, it triggered a feverish search for alternatives that can perform the myriad functions of this agricultural and structural fumigant. Nowhere is the search more keen than in California, where 19 million pounds of methyl bromide are used annually - one-third of North America's total use and $14 \%$ of worldwide use.

Because bromine atoms from the volatile compound are thought to break down the stratospheric ozone layer, the Montreal Protocol (an international agreement to restrict ozone depletors) calls for a voluntary $25 \%$ worldwide methyl bromide reduction by 2000 . "Some countries are asking for a change in the Montreal Protocol to move the phaseout date to 1997 due to the alleged damage to the ozone," said Vernard Lewis, UC Berkeley urban entomologist and chair of the commodities and structural fumigation committee of California's Methyl Bromide Alternatives Task Force.

Methyl bromide fumigation (both preplant and postharvest) is a widely used weapon for killing a wide array of diseases, nematodes, insects and weeds on more than 60 crops. It is also a mainstay of pest control in food processing plants and structural fumigations.

The United States, which accounts for $41 \%$ of the world's use of methyl bromide, is the only country to ban it outright. Beginning this year, the U.S. Environmental Protection Agency (EPA) has frozen production and importation of the soil and postharvest fumigant to 1991 levels. No schedule to actually pare down $\mathrm{MBr}$ use has been imposed, so users will not actually feel the pinch until 2001 when production and importation cease.

"Because methyl bromide is being phased out over a decade, it presents a unique situation," noted Frank Zalom, Director of UC's Statewide Integrated Pest Management Project. "In most cases, pesticides have disappeared more precipitously, either when manufacturers voluntarily withdrew them or government agencies suspended or cancelled them. This situation presents an opportunity for scientists to analyze the economic, environmental and health impacts of both methyl bromide and the alternatives. Are the substitute substances and practices better or worse? Are scientists sure that agricultural use of methyl bromide is the significant factor it is currently assumed to be in ozone depletion? What will be the social implications of the loss of such a widely used material on farmers and farm communities? What mitigation measures could be proposed to buffer losses?"

In fact, recent scientific evidence has raised questions about the impact of agricultural $\mathrm{MBr}$ use. Most people agree that methyl bromide is an ozone depletor, but fumigation may not be the major contributor. Oceans are reservoirs of methyl bromide produced by plankton and may contribute half the releases (as reported by Khalil, Rasmussen and Gunawardena in $J$. Geophys Res.). Scientists at Max Planck Institute for Chemistry revealed (in Science March 1994) that biomass burning - such as forest fires and fires to clear land - also releases gaseous methyl bromide and that this may account for $30 \%$ of the methyl bromide in the atmosphere. Current emission estimates assume that no methyl bromide is destroyed in the soil, so a team of UC Riverside and USDA researchers is conducting experiments to measure how much soil-applied methyl bromide ends up in the air.

"Enough questions are being asked that we may not lose it entirely," said Doug Gubler, UC

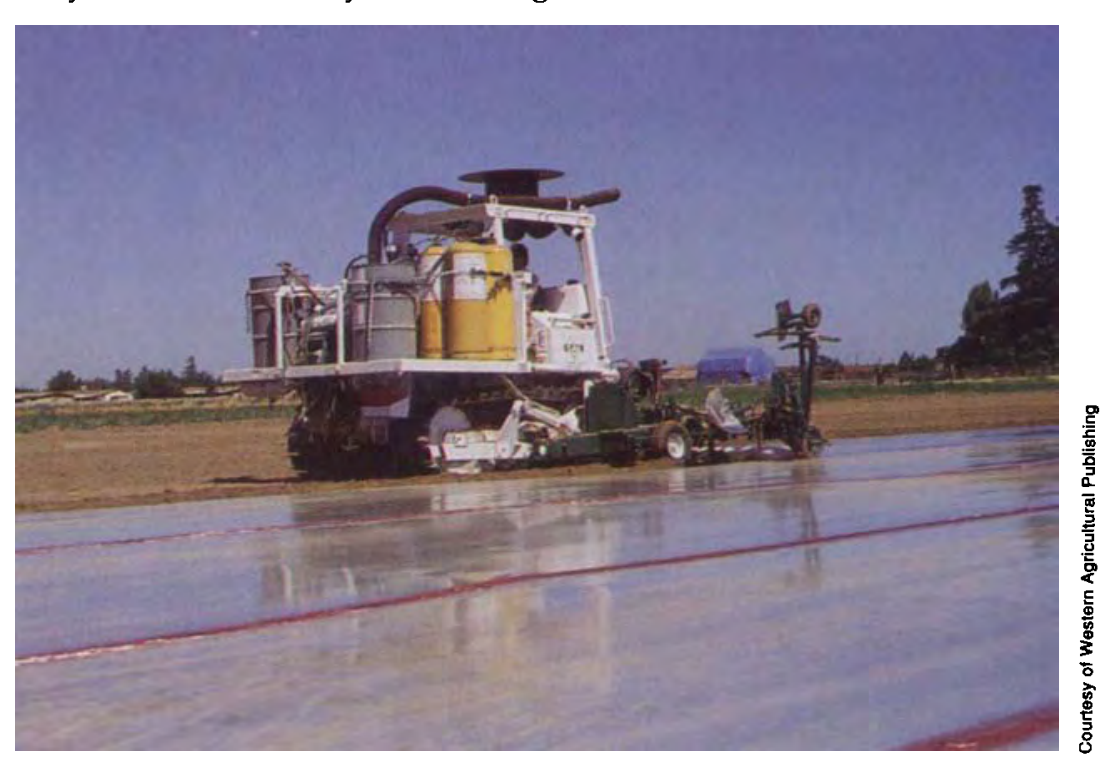

Methyl bromide regulations now require equipment modifications to reduce worker exposure, such as fans to blow fresh air toward the tractor driver. 
Davis Plant Pathologist. "At the same time, we're trying to make plans for the day it does happen."

One thing certain is that industries will be affected differently by the loss of methyl bromide, as discussed by Yarkin et al. in this issue. The primary use of methyl bromide, accounting for $85 \%$ of the 19 million pounds used in California in 1992, is preplant soil fumigation to protect crops from nematodes, disease and other soilborne pests. According to California's Department of Pesticide Regulation (DPR) pesticide use reports, the state's top methyl bromide users in 1992 were strawberries at 4.7 million pounds, grapes at 2 million pounds, almonds at 1.5 million pounds and outdoor container plants at 1.06 million pounds.

\section{Soil fumigation}

For California's strawberry industry, injecting a mix of methyl bromide and chloropicrin under polyethylene film in strawberry fields before planting has become a cornerstone practice to control weeds, soil-borne diseases, snails, slugs, weevils and nematodes.

“Until recently the combination of methyl bromide and chloropicrin was considered an ideal method because it is effective and leaves no residues," said Frank Westerlund, California Strawberry Commission research director.

\section{Recent state restrictions on methyl bromide}

In addition to federal action, the state of California has imposed its own restrictions on methyl bromide.

- In April 1992, out of concern about animal studies indicating neurotoxic effects and possible birth defects, DPR mandated longer aeration periods following structural fumigation to protect persons returning to the buildings.

- On January 1, 1993, Cal/EPA's Office of Environmental Health Hazard Assessment (OEHHA) added methyl bromide as a structural fumigant to the Proposition 65 list of chemicals that may cause birth defects.

- On January 1, 1993, DPR imposed new permit conditions for field fumigations to reduce worker exposure. These conditions include equipment modifications, restricted work hours, reduced application rates, treated acreage limits and establishment of buffer zones to protect people living or working near fumigated fields.

- On May 5, 1994, a OEHHA Advisory Board committee of toxicologists unanimously agreed that methyl bromide should not be listed as a reproductive toxicant under Prop. 65 for uses other than structural fumigation.
To ease the transition away from the broad spectrum fumigant, the state's strawberry industry has been granted $\$ 150,000$ from EPA and $\$ 200,000$ from USDA to help fund research for alternatives.

Gubler, UC Riverside plant pathologist Albert Paulus, and other UC scientists in cooperation with the strawberry commission have designed a comprehensive research program, including plant breeding for disease and pest resistance, small plot work to examine new application strategies and compounds, large field trials and studies of soil disease and pest complexes in a controlled environment. This season they are evaluating the efficacy of traditional chemicals including chloropicrin, metam sodium, dazomet and 1,3-D.

"In our first effort, we're looking for a quick fix," explained Westerlund. "That's 75\% of our research effort. We expect to continue that next year. In our 5-year plan, those efforts would drop to $20 \%$ and nonchemical alternatives would jump to $80 \% . "$

Strawberries are especially susceptible to diseases, including black root rot complex, Phytophthora root rot and Verticillium wilt, which is the most severe pathogen. Without fumigation, crops may grow well for 2 or 3 years, Gubler said, "but after high populations of these organisms build up, those acres probably would be taken out of strawberries."

Researchers examining the effects of not fumigating may learn that damaging organisms rebound faster than expected. "In this first year, a number of problems have occurred quite early," in Oxnard plots, said Mike Coffey, UC Riverside plant pathologist. "There's definitely significant disease. We're seeing close to $50 \%$ loss in production in just 1 year." Early harvest data from Gubler's unfumigated plot on the Central Coast showed a 25 to $30 \%$ yield loss.

Coffey was surprised to find that the usual suspects were not to blame. In the past, Verticillium wilt and Phytophthora were the primary causes of root damage. However, Coffey said, "In Oxnard, neither is responsible for yield losses. It's Pythium and Fusarium species that we're isolating mainly."

The strawberry industry already has a jump on breeding for genetic resistance, Gubler said, noting that plant pathologists and breeders have identified genetic sources that are resistant to Verticillium wilt, Phytophthora, powdery mil- 
dew and anthracnose. However, it takes about 10 years to develop a commercial variety and breeding for quality could lengthen the process.

Although stockpiling the product is legal, the quantities needed render that idea impractical, Westerlund said.

Grape and almond growers routinely fumigate soil with methyl bromide before planting to improve plant growth in the early years. Alternatives may be difficult to find because not all the benefits of fumigation are known, according to UC Riverside nematologist Mike McKenry (see p. 22).

In addition, several alternative chemicals have been eliminated from use in California, and others raise concerns of their own. In 1991 the sole manufacturer of the soil fumigant Vorlex (Methyl isothiocyanate + 1,3-D) voluntarily cancelled the product due to the prohibitive cost of reregistration. In 1990, DPR suspended all permits for use of Telone (1,3-D), another soil fumigant, after significant concentrations were detected in the air. Chloropicrin, a fungicide used in soil treatments, faces suspension under the California Birth Defect Prevention Act (SB 550) because registration information from the manufacturer is incomplete. If the current appeal is denied, production will cease and existing supplies will only be sold during the next two years. Chloropicrin also generates ozone-depleting chlorocarbons.

\section{Postharvest fumigation}

Postharvest applications of methyl bromide are critical for some commodities. In-shell walnuts, apples and cherries and other commodities are fumigated before shipping to satisfy the phytosanitary requirements of foreign governments. Gary Obenauf, director of research and technical services for Fresno-based Prune, Raisin and Walnut Research, estimated that about 95\% of quarantined commodities depend on methyl bromide fumigations, so halting them would dramatically affect U.S. trade. "Overnight it would stop international commerce for a lot of commodities," Obenauf said.

The consequences sound severe, but EPA does not aim to cripple the agricultural industry. "If there are certain areas where no alternative is found by 2001, EPA will support a limited number of essential uses and exemptions," confirmed EPA spokesman Bill Thomas, adding, "They would have to be approved by Congress."
For walnuts, there are currently no satisfactory alternatives. In some cases, phosphine, which is undergoing re-registration, can be used, but it takes longer. In-shell walnut fumigations with methyl bromide treatments take 12 to 24 hours, while phosphine takes 4 to 7 days. "If you need to get a shipment out on time, it can make a tremendous difference," Obenauf said. The longer treatment time in turn creates a need for greater treatment space.

Obenauf is a member of the Crop Protection Coalition, a national organization of more than 30 agricultural commodities formed to address methyl bromide issues. In addition to seeking alternatives, they are looking at ways of reducing or eliminating the problem associated with ozone depletion by recirculating or recycling the gas used in commodity fumigations in a closed system.

\section{Structural fumigation}

Structural fumigation accounts for only about $5 \%$ of methyl bromide used, but because it can be used in a lot of different circumstances and on a wide variety of pests, replacing it will be a challenge, said Eric Paulsen, director of education for Pest Control Operators of California, based in West Sacramento. "For each insect or place, we have to find a specific product," he said.

Only two fumigants, methyl bromide and sulfuryl fluoride (Vikane), are available to control powder post beetles and drywood termites, according to Vernard Lewis. Methyl bromide is the preferred pesticide to control powder post beetles because it acts as an ovicide, killing eggs as well as adult beetles. Not only is sulfuryl fluoride more expensive than methyl bromide $\$ 10$ per pound versus $\$ 3$ per pound - pest control operators must use 10 times as much of the chemical to treat for drywood termites.

Food processing plants will lose the convenience of fumigating with methyl bromide. Unlike methyl bromide, for which there are allowable limits in food, sulfuryl fluoride has no food label, so all food must be removed before fumigation. Lewis noted that hydrogen phosphine gas can be used around food, but it acts slower and resistance has appeared in some pests.

USDA has appropriated increasing funds for researching methyl bromide alternatives, with substantial amounts earmarked for California $\$ 889,000$ of the $\$ 7.5$ million for $1993, \$ 1.2$ million of the $\$ 8.5$ million in 1994 and $\$ 4$ million of the \$18.5 million in 1995 .
- Editor 